\title{
Correction to: Time Delay Compensation of a Robotic Arm based on Multiple Sensors for Indirect Teaching
}

\author{
Published online: 23 September 2021 \\ c) Korean Society for Precision Engineering 2021

\section{Correction to: \\ International Journal of Precision Engineering and Manufacturing \\ https://doi.org/10.1007/s12541-021-00542-w}

Xiaolu Zhang $^{1} \cdot$ Dongeon Kim $^{1} \cdot$ Jinuk Bang ${ }^{1} \cdot$ Jangmyung Lee $^{1}$ (I)

Due to an unfortunate oversight during the correction process the author name of Dongeun Kim has been given incorrect in the author line as well as in the biography. It should read: Dongeon Kim.

Further the biography of Jinuk Bang has been given erroneously. It should read:

Jinuk Bang received his BS degree in electronics engineering from Silla University, South Korea, in 2017 and his MS degree in electronics engineering from Pusan National University, South Korea, in 2019. He is currently working on a $\mathrm{PhD}$ at Pusan National University. His research interests include motor control, sensor control, and driving robots.

The original article has been corrected.

Publisher's Note Springer Nature remains neutral with regard to jurisdictional claims in published maps and institutional affiliations.

The original article can be found online at https://doi.org/10.1007/ s12541-021-00542-w.

Jangmyung Lee

Jmlee@pusan.ac.kr

Dongeon Kim

dongeon1696@pusan.ac.kr

Jinuk Bang

jinuk1696@pusan.ac.kr

1 Department of Electronics Engineering, Pusan National

University, 63-2 Jangjeon-dong, Geumjeong-gu,

Busan 46241, Korea 